MLM- 1412

TID-4500
UC-4 Chemistry. C . 3.00

\title{
LOADING OF SULFONIC ACID TYPE CATION EXCHANGE RESINS WITH TETRAVALENT AND HEXAVALENT PLUTONIUM-238
}
G. L. Silver
O. R. Buzzelli

Date: May 2, 1966

Issued: August 14, 1967

\section{LEG AL NOTICE}

This report was prepared as an account of Government sponsored work. Neither the United States, nor the Commission, nor any person acting on behalf of the Commission:

A. Makes any warranty or representation, expressed or implied, with respect to the accuracy, completeness, or usefulness of the information contained in this report, or that the use of any information, apparatus, method, or process disclosed in this report may not infringe of any information, apparatus privately owned rights; or
B. Assumes any liabilities with respect to the usie of, or for damages resulting from the use of any information, apparatus, method, or process disclosed in this report.

As used in the above. "person acting on behalf of the Commission" Includes any employee or contractor of the Commission, or employee of such contractor, to the extent that such employee or contractor of the Commission, or employee of such contractor prepares, disseminates, or provides access to, any information pursuant to his employment or contract with the Commission, or his employment with such contractor.

This documem is PUBLICLY RELISABLS

$26 / 2$

Dater

efricia

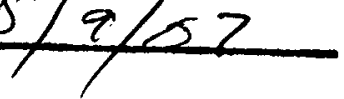

MONSANTO RESEARCH CORPORATION A Subsidiary of Monsanto Company

MOUND LABORATORY

Miamisburg, Ohio

operated for

\section{UNITED STATES ATOMIC ENERGY COMMISSION}

U.S. GOVEAMMENT CONTAACT MO. AT. J3.1.GEM.53 


\section{DISCLAIMER}

This report was prepared as an account of work sponsored by an agency of the United States Government. Neither the United States Government nor any agency Thereof, nor any of their employees, makes any warranty, express or implied, or assumes any legal liability or responsibility for the accuracy, completeness, or usefulness of any information, apparatus, product, or process disclosed, or represents that its use would not infringe privately owned rights. Reference herein to any specific commercial product, process, or service by trade name, trademark, manufacturer, or otherwise does not necessarily constitute or imply its endorsement, recommendation, or favoring by the United States Government or any agency thereof. The views and opinions of authors expressed herein do not necessarily state or reflect those of the United States Government or any agency thereof. 


\section{DISCLAIMER}

Portions of this document may be illegible in electronic image products. Images are produced from the best available original document. 


\section{TABLE OF CONTENTS}

\section{Page}

Summary

3

Introduction

4

Experimental

5

Discussion

6

Plutonium(VI)

9

References

II 


\section{SUMMARY}

The equilibrium of plutonium-238 with sulfonic acid type cation exchange resins is described. A threedimensional model useful in characterizing the loading of these resins with plutonium-238 is presented.

The loading of the resins with hexavalent plutonium-238 is followed by loading of the resins with internally generated tetravalent plutonium. 


\section{INTRODUCTION}

Because of the utility of anion exchange resins in plutonium purification procedures, much attention has been given to the behavior of macro amounts of plutonium with this type of resin.' The nature of the loading of cation exchange resins with macro amounts of plutonium has not been investigated as thoroughly. This report describes the loading of tetravalent and hexavalent plutonium-238 by strong acid cation exchange resins. 


\section{EXPERIMENTAL}

The resins used in this study were the $50 \mathrm{~W}-\mathrm{X} 8$ type prepared by the Dow Chemical Company. The resins had been sized and washed by Bio-Rad Laboratories of Richmond, California, and were purchased directly from this source.

For purposes of calculation, it was assumed that in solutions of low acidity, in which valence changes in the plutonium occur by disproportionation, only the tetravalent species is absorbed by the resin. All plutonium analyses were made by alpha counting, and acidities were determined by the citrate method using phenolphthalein. Since the capacity of the Dowex $50 \mathrm{~W}$ resins used was approximately 5.1 meq per dry gram, the resins at $100 \%$ theoretical loading could contain approximately $300 \mathrm{mg}$ of plutonium per gram of dry resin. Loading was studied by allowing an accurately measured quantity of plutonium nitrate in nitric acid to equilibrate for several hours with an accurately weighed portion of dry resin. By withdrawing and analyzing samples periodically, the time required to reach equilibrium and the rate of the loading could be ascertained.

In contrast to the absorption by anion exchange resins,' the absorption of plutonium by cation exchange resins appears to be relatively rapid; only a few hours are required to reach apparent equilibrium. Loading was complete in about $4 \mathrm{hr}$ and no change in the quantity of the absorbed plutonium was apparent for several more hours. After $24 \mathrm{hr}$, however, the resin appeared to gradually release plutonium. This is attributed to radiation damage to the resins which results in a decreased capacity for the cationic plutonium. ${ }^{2}$ Even after $48 \mathrm{hr}$, however, the maximum amount lost by the resins was not found to be more that $10 \%$ of the initially bound plutonium. 


\section{DISCUSSION}

It was apparent at the beginning of this study that the loading of plutonium by cation exchange resins would be related to the acidity of the medium from which loading occurred. The relationship of acidity to loading of the resins was examined by two sets of experiments: loading versus acidity in the presence of a predetermined quantity of plutonium at constant volume, and loading versus plutonium concentration at constant acidity. The first of these studies was performed by allowing several portions of dried resin of equal weight to equilibrate with equal quantities of plutonium at constant volume in various concentrations of nitric acid. Typical results are shown in Figure 1, where the degree to which the resin is loaded (as percent load) is plotted against the hydrogen ion concentration. In this experiment, both the percent load and equilibrium concentration of the plutonium varied with kitlity. The second set of loading experiments elucidated the behavior of the percent load at cor . ic..... tit as tre equilibrium concentration of plutonium was changed. These data proved more difficult to obtain, and the curves of Figure 2 , which show the relationship of percent load and equilibrium plutonium concentration at constant acidity, have been constructed from equilibrium studies at acidities which were not always identical, but which were approximately equal $\left(\Delta H^{+}<0.1 \mathrm{M}\right)$. Since loading is quite sensitive to acidity, points describing the curves of Figure 2 have been calculated using a correction factor:

$\%$ Load Correction $=\frac{\Delta \% \text { Load }}{\Delta H^{+}}\left[H_{\text {desired }}^{+}-H^{+}\right.$obstrved $]$

$\%$ Load Found $+\%$ Load Correction $=\%$ Load Corrected

$H^{+}$desired is the value of the acidity at which the true percent load is desired (i.e., one of the acidity values in Figure 2). The value of the ratio $\Delta \% \mathrm{Load} / \Delta H^{+}$is obtained from curves of the type shown in Figure 1. It is the slope at a particular percent load on the curve which best approximates the conditions under which the data of Figure 2 were obtained.

In order to express the three variables important in describing the resin loading behavior - percent load, equilibrium concentration of plutonium, and acidity a three-dimensional diagram is needed. Such a diagram is shown in Figure 3. It was constructed using data such as that shown in Figure 2. In this diagram, the three axes represent equilibrium acidity $\left(H^{+}\right)$, equilibrium concentration $\left(C_{E}\right)$, and percent load. At low acidities the percent load rises quickly with the increasing equilibrium concentration, and the curving boundary of the solid lies quite close to the $H^{+}-\%$ Load plane. The intersection of the surface with the $H^{+}-C_{E}$ plane has been shown in Figure 3 as intersecting the $H^{+}$axis. Since this intersection represents the behavior of plutonium(IV) at zero percent load, the nature of the solid in this region of the $\mathrm{H}^{+}$axis is best described by the many studies of the distribution coefficient of plutonium(IV) with cation exchange resins. ${ }^{3}$ The curves of Figure 2 provide profiles of the surface of the solid along planes of constant acidity.

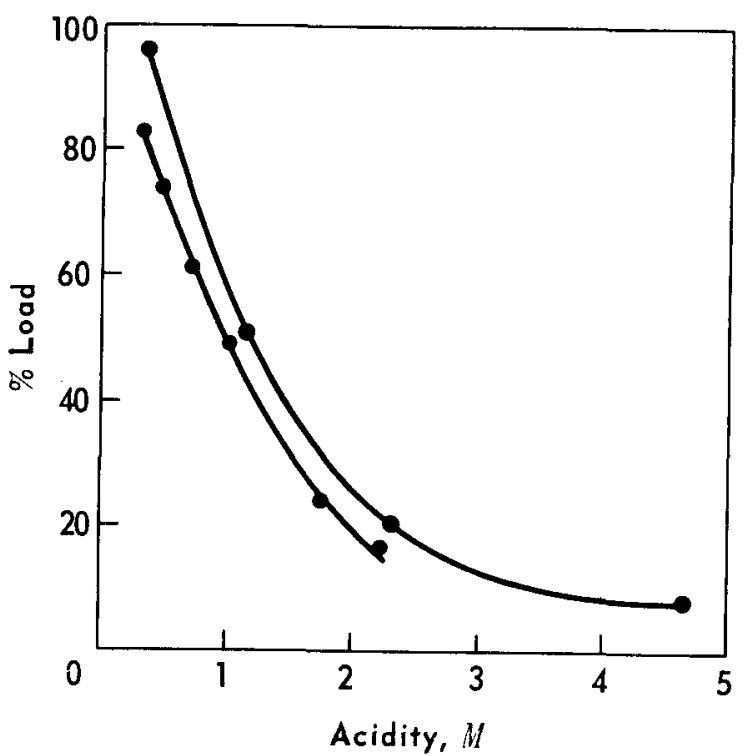

Figure 1. Absorption of Plutonium(IV) by Dowex $50 W-X 8$. 


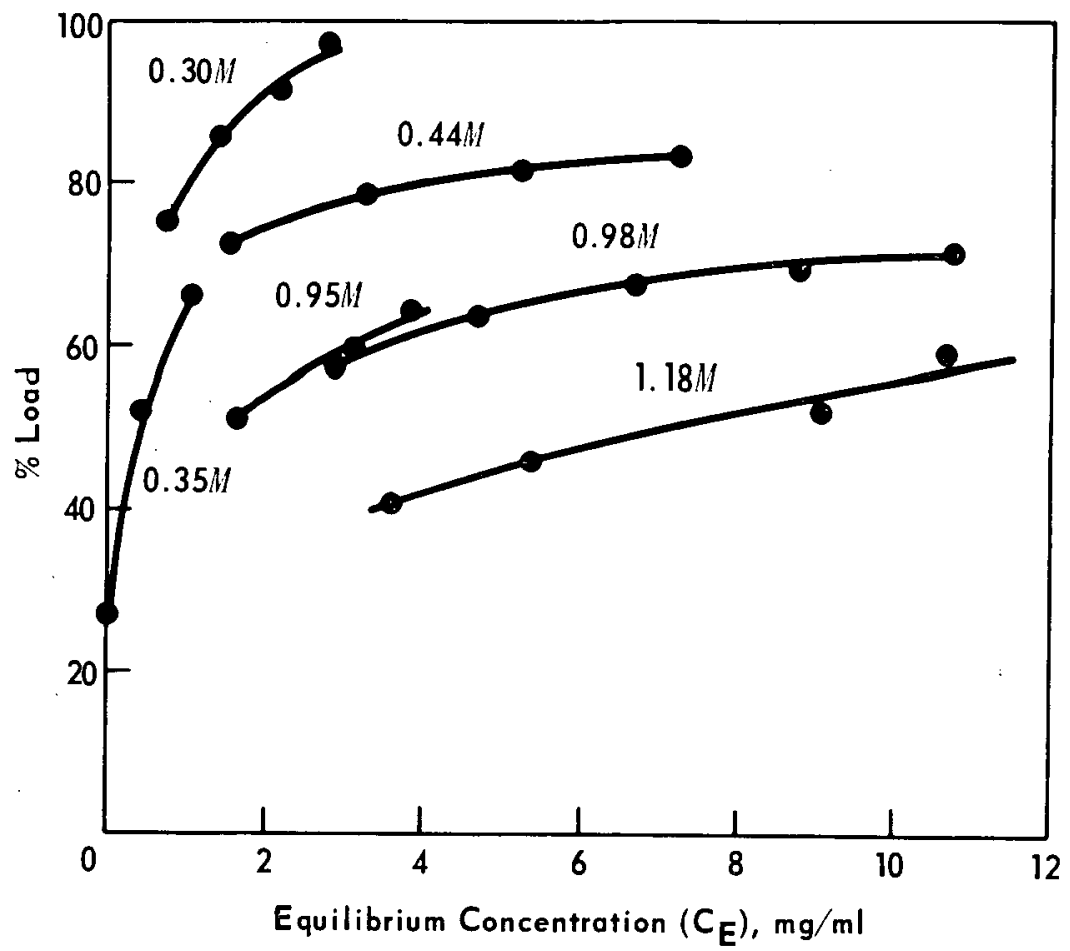

Figure 2. Absorption of Plutonium(IV) by Dowex $50 W-X 8$.

The constant volume loading of plutonium(IV) as a function of acidity can be described as a line along the surface of Figure $\dot{3}$. This line is rather difficult to construct on an a priori basis without knowledge of the exact manner in which the acidity, equilibrium concentration of plutonium, and percent load are related. It may, nevertheless, be sketched on the solid from a knowledge of the behavior of the variables governing the percent load. Such information is available in Figures $\mid$ and 2 . The curves of the percent load as a function of acidity at constant volume and constant quantity of plutonium (Figure 1) are helpful in sketching this line. These curves are projections of the constantvolume load line into the $\mathrm{H}^{+}-\%$ Load plane. These projections indicate that the constant-volume load line follows a concave path along the surface of Figure 3.

The specification of constant volume allows one to ascertain the projection of the constant-volume load line into the $\%$ Load- $C_{E}$ plane. Since unloading the resin increases the equilibrium concentration of plutonium in the solution from which loading occurs, this projection must be of the form

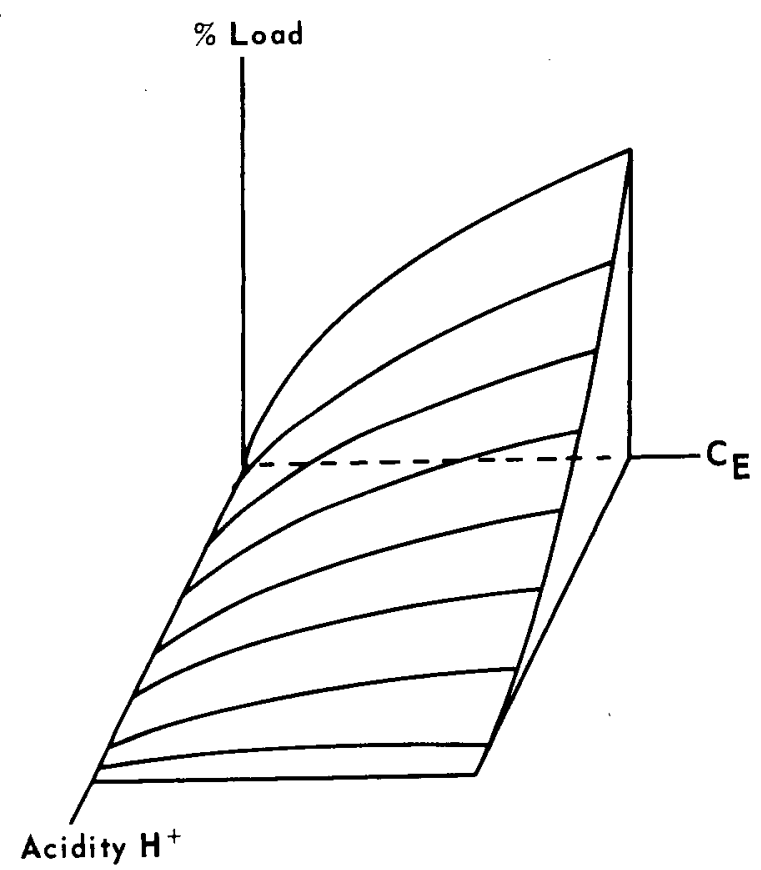

$$
\frac{d \% \text { Load }}{d C_{E}}=-K \quad\left(\begin{array}{c}
\text { constant quantity } \\
\text { of plutonium }
\end{array}\right)
$$

Figure 3. Surface Describing Absorption of Plutonium(IV) by Dowex 50W-X8. 
(i.e., a straight line). The value of $K$, for example, in a solution containing $\mathrm{I} g$ of resin in a volume of $100 \mathrm{ml}$ would be

$$
K=\frac{d \% \text { Load }}{\frac{(d \% \text { Load } / \text { l00)(300) }}{100}}=33
$$

The projection of the constant-volume load line into the $H^{+}-C_{E}$ plane depends upon the loading volume and the quantity of resin loaded. Since, however, $d \% \mathrm{Load} / \mathrm{d} H^{+}$is not constant, this projection is not a straight line. This function can nevertheless be calculated from data used to prepare Figure I. One typical plot of this projection, taken from one of the projections of the type shown in Figure $\mathrm{I}$, is sketched in the $H^{+}-C_{E}$ plane in Figure 4.

Figure 2 suggests it might be possible to formulate an equilibrium expression for the loading of plutonium (IV) ions on a cation exchange resin. This expression might be

$$
P u^{4^{+}}+4 R H=P u R_{4}+4 H^{+} \quad K_{e q}=\left(P u R_{4}\right)\left(H^{+}\right)^{4} /\left(P \dot{u}^{4}\right)(R H)^{4}
$$

where: $P u R_{4}=$ sites occupied by $\mathrm{Pu}^{4+}$ assuming each $\mathrm{Pu}^{4}$ occupies four active resin sites $=\%$ Load $/ 4$.

$$
\begin{aligned}
& \text { RH }=\text { free resin sites found by difference } \\
& \qquad \log K+\log \frac{(R H)^{4}\left(P u^{4}\right)}{P u R_{4}}=4 \log H^{+}
\end{aligned}
$$

A plot of $\log (R H)^{4}\left(P u^{4}\right) / P u R_{4}$ versus $\log H^{+}$is shown in Figure 5 . The predicted slope is 4.0 .

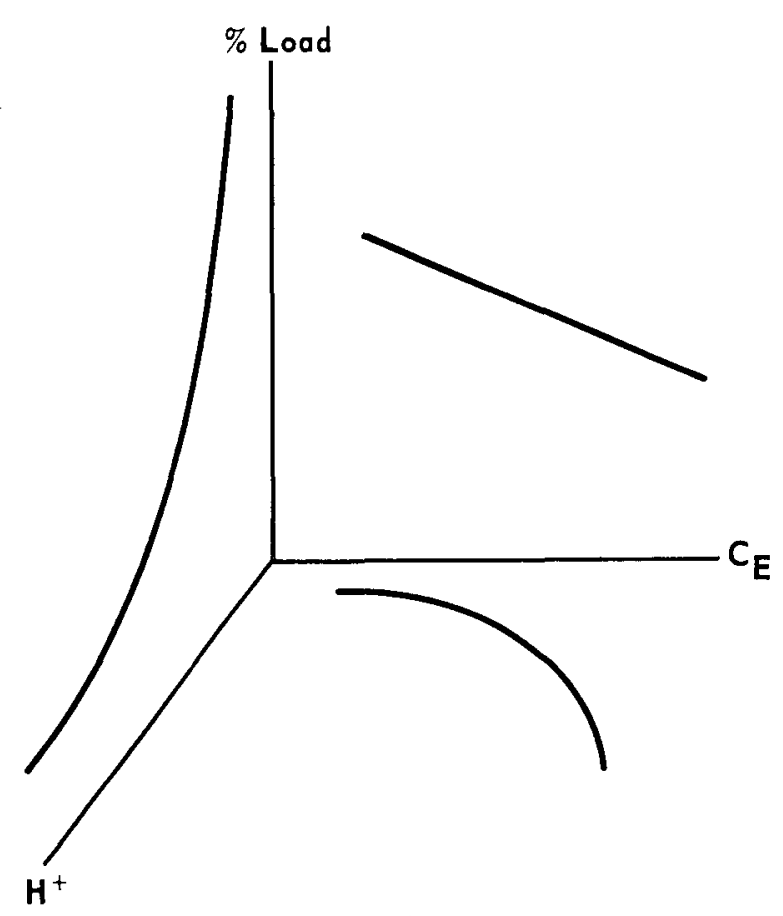

Figure 4. Projections of Typical ConstantVolume Load Line (Constant Quantity of Plutonium, Variable Acidity).

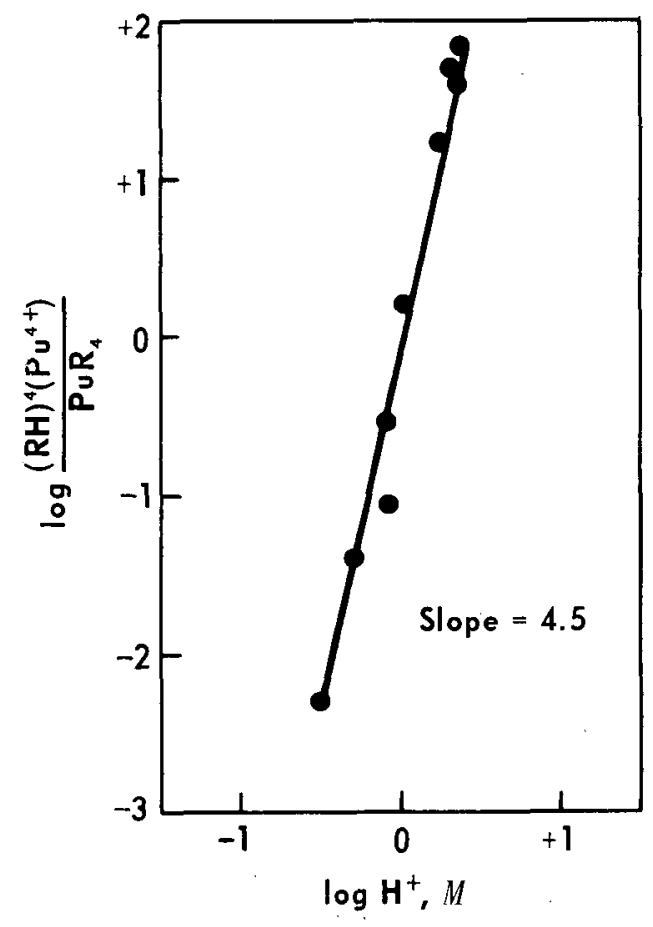

Figure 5. Plot Based on Equation 4. 
Points were adapted from the data used to prepare Figure 2, and appear to approximate a straight line over a wide range of loading. The slope of the line is found to be 4.5 .

One of the more interesting aspects of this study of the loading of plutonium- 238 by cation exchange resins was the discovery that in solutions initially containing only plutonium(IV) there will be a gradual "wandering" of the average valence. This yields solutions which, at equilibrium, contain largely the tetravalent and trivalent species, even in low acidity. The equilibrium concentration of plutonium( $V I)$ is much less than predicted by disproportionation. This "valence wandering" is complete in a period of a few hours. The loading of plutonium by cation exchange resins does not appear to be complicated by the presence of plutonium(VI) under any circumstances. This was determined by observing the spectra of the solutions for characteristic bands of the three species, and by examining spectral changes by the method of complementary tristimulus colorimetry.

\section{PLUTONIUM(VI)}

The loading of plutonium( $V I)$ by Dowex $50 \mathrm{~W}-\mathrm{X} 8$, was examined in the presence of plutonium(IV) and in the presence of no other plutonium species. Plutonium(VI) was prepared by oxidizing the tetravalent species with divalent silver oxide in dilute nitric acid. The loading of plutonium (i.e., total plutonium) from a mixture of a tetravalent and a hexavalent species does not appear to proceed as rapidly as does loading from a solution of the tetravalent species alone. Loading is also not as extensive in this case and may be decreased because of the competition for the resin sites by both the hydrogen ions and the silver ions.

Solutions of plutonium(IV) and plutonium(VI) from which the resin loaded were examined by the method of complementary tristimulus colorimetry. The complementary color points of such solutions at first move in the direction of the complementary color point of pure plutonium $(V I)$, and then reverse the direction of movement and proceed in the direction of the complementary color point of pure plutonium(IV). From independent studies, it was later determined that in dilute nitric acid solutions the concentration of plutonium (VI) gradually decreases until nearly all of the plutonium is in the trivalent and tetravalent states. The initial movement of the complementary color points of solutions of plutonium(VI) and plutonium(IV) containing cation exchange resin toward the color point of pure plutonium(VI) indicates that it is the tetravalent species and not the hexavalent species which is absorbed preferentially by the resin. The color point of a control solution in which there was no resin moves directly toward the color point of pure plutonium(IV).

In Figure 6 is shown the loading of plutonium by cation exchange resins containing only plutonium(VI) initially. This figure represents the loading of plutonium expressed both as the hexavalent and tetravalent state at three different acidities. It appears that a metastable equilibrium is quickly reached, followed by a slow increase in loading. This metastable region probably represents the loading of plutonium(VI) by the resin. In each case the characteristic peak of plutonium(IV) near $475 \mathrm{~m} \mu$ appeared after several hours. The increased loading after several hours is due to the loading of plutonium(IV) by the resin as this plutonium species is gradually generated in the solution. 


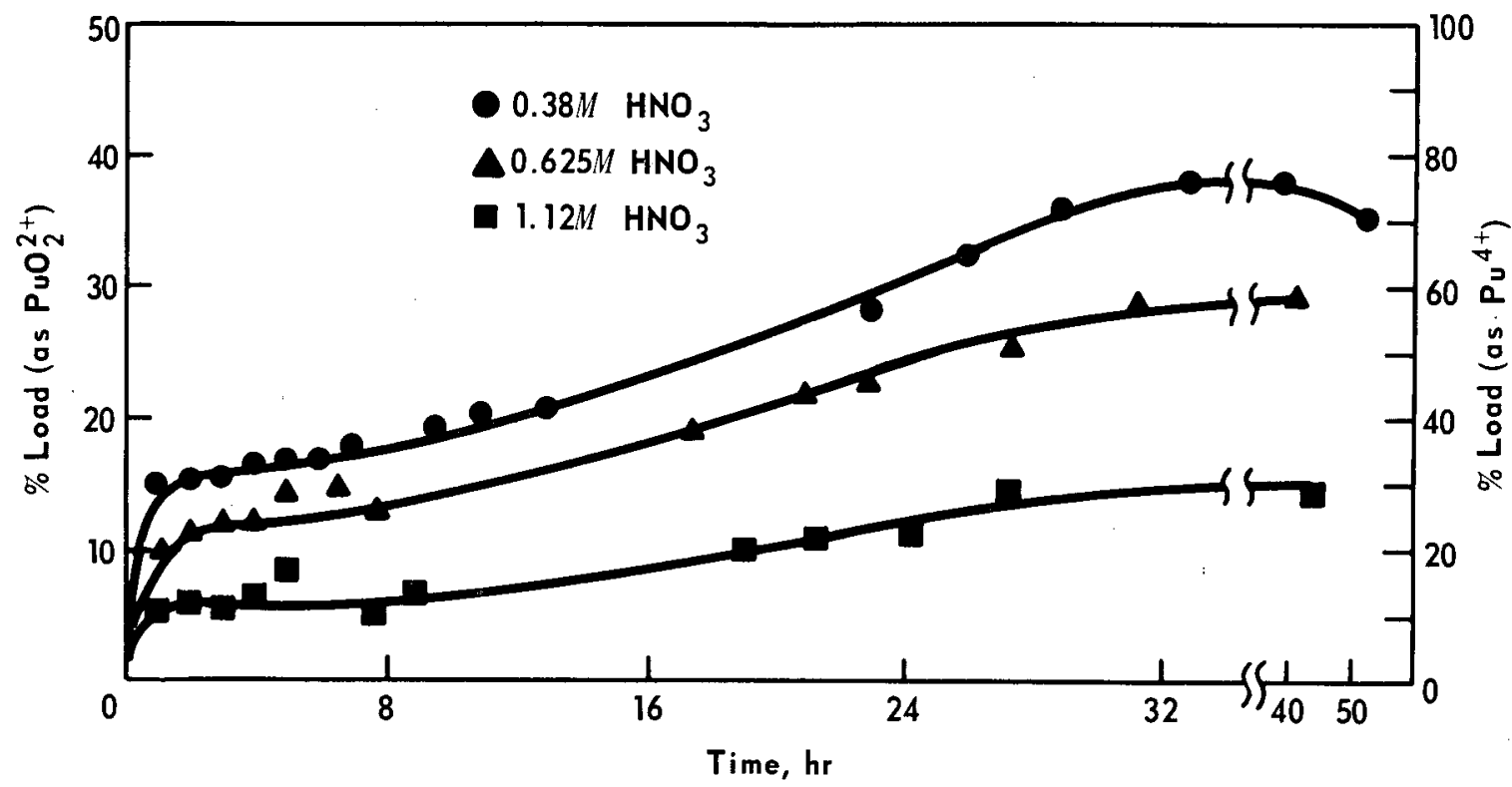

Figure 6. Loading of Plutonium by Dowex 50W-X8 from Initially Pure Hexavalent Plutonium. 


\section{REFERENCES}

I. J. L. Ryan and E. J. Wheelwright, Ind. Eng. Chem., 51, 60-5 (1959).

2. M. D. Peterson, G. T. Fisher and W. D. Threadgill, Radiation Stability and Inorganic Radiochemistry, AEC Report TID-21385 (September 30, 1964).

3. F. R. Bruce, J. M. Fletcher and H. H. Hyman (eds.), "Process Chemistry", Vol. 2, Progress in Nuclear Energy, Series III, p. 377. 